\title{
Patient-centered contraceptive care for medically complex patients
}

\author{
Appropriate counseling for an obese patient with seizure disorder and \\ migraines
}

\author{
Sarah Horvath, MD, MSHP
}

\section{IN THIS} ARTICLE

\section{CDC MEC risk categories \\ page 27}

\section{Crafting your counseling approach \\ page 27}

\section{Shared decision} making page 28

\begin{abstract}
CASE Patient-centered counseling for contraception

A 19-year-old woman (G0) with moderately well-controlled seizure disorder while taking levetiracetam, who reports migraines, and has a BMl of $32 \mathrm{~kg} / \mathrm{m}^{2}$ presents to your office seeking contraception. She is currently sexually active with her second lifetime partner and uses condoms inconsistently. She is otherwise healthy and has no problems to report. Her last menstrual period (LMP) was 1 week ago, and a pregnancy test today is negative. How do you approach counseling for this patient?
\end{abstract}

\section{The modern contraceptive patient}

Our patients are becoming increasingly medically and socially complicated. Meeting the contraceptive needs of patients with multiple comorbidities can be a daunting task. Doing so in a patient-centered way that

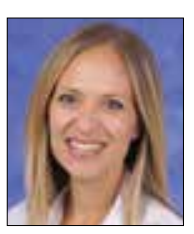

Dr. Horvath is Assistant Professor, Department of Obstetrics and Gynecology, Penn State Hershey Medical Center, Hershey, Pennsylvania.

The author reports no financial relationships relevant to this article.

doi: 10.12788 /obgm.0083 also recognizes the social contexts and intimacy inherent to contraceptive care can feel overwhelming. However, by employing a systematic approach to each patient, we can provide safe, effective, individualized care to our medically complex patients. Having a few "go-to tools" can streamline the process.

Medically complex patients are often told that they need to avoid pregnancy or optimize their health conditions prior to becoming pregnant, but they may not receive medically-appropriate contraception. ${ }^{1-3}$ Additionally, obesity rates in women of reproductive age in the United States are increasing, along with related medical complexities. ${ }^{4}$ Disparities in contraceptive access and use of particular methods exist by socioeconomic status, body mass index (BMI), age, and geography. ${ }^{5,6}$ Evidence-based, shared decision making can improve contraceptive satisfaction. ${ }^{7}$

Clinicians need to stay attuned to all options. Staying current on available contraceptive methods can broaden clinicians' thinking and allow patients more choices that are compatible with their medical needs. In the last 2 years alone, a 1-year combined estrogen-progestin vaginal ring, a drospirinone-only pill, and a nonhormonal spermicide have become available for prescription. ${ }^{8-10}$ Both 52 mg levonorgestrel-containing intrauterine devices (IUDs) are now US Food and Drug Administration (FDA)approved for 6 years, and there is excellent data for off-label use to 7 years. ${ }^{11}$ 
Tools are available for use. To ensure patient safety, we must evaluate the relative risks of each method given their specific medical history. The Centers for Disease Control and Prevention (CDC) Medical Eligibility Criteria (MEC) provides a comprehensive reference for using each contraceptive method category with preexisting medical conditions on a scale from 1 (no restrictions) to 4 (unacceptable health risk) (TABLE 1). ${ }^{12}$ It is important to remember that pregnancy often poses a larger risk even than category 4 methods. With proper counseling and documentation, a category 3 method may be appropriate in some circumstances. The CDC MEC can serve as an excellent counseling tool and is available as a free smartphone app. The app can be downloaded via https://www .cdc.gov/reproductivehealth/contraception /mmwr/mec/summary.html (TABLE 2).

In a shared decision-making model, we contribute our medical knowledge, and the patient provides expertise on her own values and social context. ${ }^{13}$ By starting the contraceptive conversation with open-ended questions, we invite the patient to lead the discussion. We partner with them in finding a safe, effective method that is compatible with both the medical history and stated preferences. Bedsider.org has an interactive tool that allows patients to explore different contraceptive methods and compare their various characteristics. While tiered efficacy models may help us to organize our thinking as clinicians, it is important to recognize that patients may consider side effect profiles, nonreliance on clinicians for discontinuation, or other priorities above effectiveness.

\section{How to craft your approach}

Developing a systematic approach to the medically complex patient seeking contraception can help to change an initially daunting task into a fulfilling experience (FIGURE 1, page 28). Begin by eliciting patient priorities. Then frame the discussion around them, rather than around efficacy. Although anecdotal reasoning can initially be frustrating ("My best friend's IUD was really painful and
TABLE 1 CDC MEC risk categories ${ }^{12}$

\begin{tabular}{c|l}
\hline Risk category & Description \\
\hline 1 & $\begin{array}{c}\text { No restriction (method can be used) } \\
\text { risks }\end{array}$ \\
\hline 2 & $\begin{array}{l}\text { Theoretical or proven risks usually outweigh the } \\
\text { advantages }\end{array}$ \\
\hline 3 & \begin{tabular}{c} 
Unacceptable health risk (method not to be used) \\
\hline 4
\end{tabular} \\
\hline Abbreviations: CDC, Centers for Disease Control and Prevention; MEC, Medical Eligibility Criteria.
\end{tabular}

\section{table 2 Resources}

\begin{tabular}{l:l}
\hline Resource & Website \\
\hline CDC Medical Eligibility Criteria & $\begin{array}{l}\text { https://www.cdc.gov/reproductivehealth/ } \\
\text { contraception/mmwr/mec/summary } \\
\text { html }\end{array}$ \\
\hline Bedsider patient information & https://www.bedsider.org/ \\
\hline Provider updates & https://providers.bedsider.org/ \\
\hline ACOG LARC Program & https://www.acog.org/programs/long- \\
& acting-reversible-contraception-larc \\
\hline Abbreviations: ACOG, American College of Obstetricians and Gynecologists; CDC, Centers for \\
Disease Control and Prevention; LARC, long-acting reversible contraception.
\end{tabular}

I don't want anything like that inside me!"), learning about these experiences prior to counseling can be incredibly informative. Ask detailed questions about medical comorbidities, as these subtleties may change the relative safety of each method. Finally, engage the patient in a frank discussion of the relative merits, safety, and use of all medically appropriate contraceptive methods. The right method is the method that the patient will use.

\section{CASE Continued: Applying our counseling} method

Upon open-ended questioning, the patient tells you that she absolutely cannot be on a contraceptive method that will make her gain weight. She has several friends who told her that they gained weight on "the shot" and "the implant." She wants to avoid these at all costs and thinks she might want to take "the pill." She also tells you that she is in college and that her daily routine varies significantly between weekdays and weekends. She definitely does not want to get 


\section{FIGURE 1 Systematic contraceptive decision- making map}

\begin{tabular}{|ll|}
\hline $\begin{array}{l}\text { Elicit Patient } \\
\text { Preferences }\end{array}$ & $\begin{array}{r}\text { - Is there anything that would make a method unacceptable } \\
\text { to you? }\end{array}$ \\
\hline $\begin{array}{c}\text { Determine } \\
\text { Safety }\end{array}$ & - CDC US MEC, other disease-specific literature \\
\hline $\begin{array}{c}\text { Shared } \\
\text { Decision- } \\
\text { Making }\end{array}$ & - Prescription of preferred patient contraceptive method \\
\hline
\end{tabular}

\section{$\overline{\text { FAST }}$ \\ TRACK}

Use open-ended questioning

to assess

the patient's

contraceptive

preferences,

and ensure

that medical

comorbidities

don't change the

safety of available

or preferred

methods pregnant until she has completed her education, which will be at least 3 years from now.

To best counsel this patient and arrive at the most appropriate contraceptive option for her, clarify her medical history and employ shared decision-making for her chosen method.

\section{Probe her seizure history}

She tells you that she has had seizures since she was a child, and the last one occurred 4 months ago when she ran out of her anticonvulsant medication. Her seizures have never been associated with her menses. This is an important piece ofinformation. The frequency of catamenial seizures can be decreased with use of any method that suppresses ovulation, such as depot-medroxyprogesterone (DMPA) injections, continuous combined hormonal contraceptive (CHC) pills or ring, or the implant. Noncatamenial seizures also can be suppressed by DMPA, which increases the seizure threshold. ${ }^{14}$ Many anticonvulsants are metabolized through cytochrome $\mathrm{P} 450$ in the liver and, therefore, interact with all oral contraceptive formulations. However, levetiracetam is not among them and may be safely taken with progestin-only pills. At this point, all contraceptive methods remain CDC MEC category 1 (FIGURE 2). ${ }^{12}$

\section{Ask migraine specifics}

It is important to clarify whether or not the patient experiences aura with her migraines. She says that she always knows when a migraine is coming on because she sees floaters in her vision for about 30 minutes prior to the onset of excruciating headache. One tool that may aid in the diagnosis of aura is the Visual Aura Rating Scale (VARS). ${ }^{15}$ The presence of aura renders all CHCs category 4 by the CDC MEC. ${ }^{12}$ (See FIGURE 2.)

\section{Discuss contraceptive pros and cons}

Have a frank discussion about the relative risks and benefits of each method. For instance, although DMPA may improve the patient's seizures, she has expressed a desire to avoid weight gain, and DMPA is the only method consistently shown in studies to do so. ${ }^{16}$ Her seizures are not associated with menses, so menstrual suppression is neither beneficial nor deleterious. Although her current medication levetiracetam does not influence the metabolism of contraceptive methods, many anticonvulsants do. Offer anticipatory guidance around seeking gynecologic consultation with any future seizure medication changes.

\section{Allow for shared decision-making on a final choice}

The patient indicated that she had been considering "the pill" when she made this appointment, but you have explained that CHCs are contraindicated for her. She is concerned that she will not be able to stick to the strict dosing schedule of a progestin-only pill. Although you inform her that the drospirinone-only pill has a more forgiving window, the patient decides that she wants a "set it and forget it" method and opts for an IUD.

\section{CASE Resolved}

Following recommendations from the American College of Obstetricians and Gynecologists (ACOG), you provide for same-day insertion of a 52-mg levonorgestrel IUD. ${ }^{17}$ You use a paracervical block in addition to ibuprofen for pain control. ${ }^{18}$ The patient undergoes same-day testing for gonorrhea and chlamydia, and she understands 
FIGURE 2 CDC MEC for case patient conditions ${ }^{12}$

\begin{tabular}{|c|c|c|c|c|c|c|c|c|c|c|c|c|c|}
\hline \multirow[t]{2}{*}{ Condition } & \multirow[t]{2}{*}{ Sub-Condition } & \multicolumn{2}{|c|}{ Cu-IUD } & \multicolumn{2}{|c|}{ LNG-IUD } & \multicolumn{2}{|c|}{ Implant } & \multicolumn{2}{|c|}{ DMPA } & \multicolumn{2}{|c|}{ POP } & \multicolumn{2}{|c|}{$\mathrm{CHC}$} \\
\hline & & $\mathbf{I}$ & $\mathbf{C}$ & $\mathbf{I}$ & C & $\mathbf{I}$ & C & $\mathbf{I}$ & C & I & C & I & C \\
\hline Epilepsy & (see also Drug Interactions) & \multicolumn{2}{|c|}{1} & \multicolumn{2}{|c|}{1} & \multicolumn{2}{|c|}{1} & \multicolumn{2}{|c|}{1} & \multicolumn{2}{|c|}{1} & \multicolumn{2}{|c|}{1} \\
\hline \multirow[t]{2}{*}{$\begin{array}{l}\text { Anticonvulsant } \\
\text { therapy }\end{array}$} & $\begin{array}{l}\text { a) Certain anticonvulsants (phenytoin, } \\
\text { carbamazepine, barbituates, primidone, } \\
\text { topiramate, oxcarbazepine }\end{array}$ & \multicolumn{2}{|c|}{1} & \multicolumn{2}{|c|}{1} & \multicolumn{2}{|c|}{2} & \multicolumn{2}{|c|}{1} & \multicolumn{2}{|c|}{3} & \multicolumn{2}{|c|}{3} \\
\hline & b) Lamotrigine & \multicolumn{2}{|c|}{1} & \multicolumn{2}{|c|}{1} & \multicolumn{2}{|c|}{1} & \multicolumn{2}{|c|}{1} & \multicolumn{2}{|c|}{1} & \multicolumn{2}{|c|}{3} \\
\hline \multirow[t]{4}{*}{ Headaches } & a) Nonmigraine (mild or severe) & \multicolumn{2}{|c|}{1} & \multicolumn{2}{|c|}{1} & \multicolumn{2}{|c|}{1} & \multicolumn{2}{|c|}{1} & \multicolumn{2}{|c|}{1} & \multicolumn{2}{|c|}{1} \\
\hline & b) Migraine & & & & & & & & & & & & \\
\hline & $\begin{array}{l}\text { i) Without aura (includes menstrual } \\
\text { migraine) }\end{array}$ & \multicolumn{2}{|c|}{1} & \multicolumn{2}{|c|}{1} & \multicolumn{2}{|c|}{1} & r & & 1 & 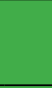 & & 2 \\
\hline & ii) With aura & & & & & & 1 & 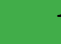 & & 1 & & & 4 \\
\hline Obesity & a) Body mass index (BMI) $\geq 30 \mathrm{~kg} / \mathrm{m}^{2}$ & & & & & & 1 & 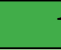 & & 1 & & & 2 \\
\hline & $\begin{array}{l}\text { b) Menarche to }<18 \text { years and } \mathrm{BMI} \geq 30 \\
\mathrm{~kg} / \mathrm{m}^{2}\end{array}$ & & & & & & 1 & 2 & & 1 & & & 2 \\
\hline
\end{tabular}

Abbreviations: CDC, Centers for Disease Control and Prevention; CHC, combined hormonal contraception; Cu-IUD, Copper intrauterine device; DMPA, depot medroxyprogesterone acetate; LNG-IUD, levonorgestrel intrauterine device; MEC; Medical Eligibility Criteria; POP, progestogen-only contraceptive pill.

that if a test is found to be positive, she can be treated without removing the IUD. You provide instruction on the importance of dual contraceptive use with barrier methods for the prevention of STIs. The patient is instructed on self-string checks, and she acknowledges that she will call if she has any concerns; no routine follow-up is required. She leaves her visit satisfied with her preferred, safe, effective contraceptive method in situ.

\section{References}

1. Lauring JR, Lehman EB, Deimling TA, et al. Combined hormonal contraception use in reproductive-age women with contraindications to estrogen use. Am J Obstet Gynecol. 2016;215:330.el-e7.

2. Mendel A, Bernatsky S, Pineau CA, et al. Use of combined hormonal contraceptives among women with systemic lupus erythematosus with and without medical contraindications to oestrogen. Rheumatology (Oxford). 2019;58:1259-1267.

3. Judge CP, Zhao X, Sileanu FE, et al. Medical contraindications to estrogen and contraceptive use among women veterans. Am J Obstet Gynecol. 2018;218:234.el-234.e9.

4. Hales CM, Carroll MD, Fryar CD, et al. Prevalence of obesity and severe obesity among adults: United States, 2017-2018. NCHS Data Brief. 2020;360:1-8.

5. Guttmacher Institute. Contraceptive use in the United States. April 2020. https://www.guttmacher.org/fact-sheet /contraceptive-use-united-states. Accessed March 22, 2021.

6. Mosher WD, Lantos H, Burke AE. Obesity and contraceptive use among women 20-44 years of age in the United States: results from the 2011-15 National Survey of Family Growth (NSFG). Contraception. 2018:97:392-398.
7. Dehlendorf C, Grumbach K, Schmittdiel JA, et al. Shared decision making in contraceptive counseling. Contraception. 2017;95:452-455.

8. Annovera [package insert]. Boca Raton, FL: TherapeuticsMD, Inc; 2020.

9. Slynd [package insert]. Florham Park, NJ: Exeltis; 2019.

10. Phexxi [package insert]. San Diego, CA: Evofem; 2020.

11. Rowe P, Farley T, Peregoudov A, et al. Safety and efficacy in parous women of a 52-mg levonorgestrel-medicated intrauterine device: a 7-year randomized comparative study with the TCu380A. Contraception. 2016;93: 498-506.

12. Centers for Disease Control and Prevention. US Medical Eligibility Criteria (US MEC) for Contraceptive Use, 2016. https://www.cdc.gov/reproductivehealth/contraception /mmwr/mec/summary.html. Accessed March 23, 2021.

13. Charles C, Gafni A, Whelan T. Shared decision-making in the medical encounter: what does it mean? (or it takes at least two to tango). Soc Sci Med. 1997;44:681-692.

14. Dutton C, Foldvary-Schaefer N. Contraception in women with epilepsy: pharmacokinetic interactions, contraceptive options, and management. Int Rev Neurobiol. 83;2008:113134.

15. Eriksen MK, Thomsen LL, Olesen J. The visual aura rating scale (VARS) for migraine aura diagnosis. Cephalalgia. 2005;25:801-810.

16. Beksinska ME, Smit JA, Kleinschmidt I, et al. Prospective study of weight change in new adolescent users of DMPA, NET-EN, COCs, nonusers and discontinuers of hormonal contraception. Contraception. 2010;81:30-34.

17. Espey E, Hofler L. Long-acting reversible contraception: implants and intrauterine devices. Practice bulletin 186. Obstet Gynecol. 2017;130:e251-269.

18. Akers AY, Steinway C, Sonalkar S, et al. Reducing pain during intrauterine device insertion: a randomized controlled trial in adolescents and young women. Obstet Gynecol. 2017;130:795-802. 